\title{
VARIA
}

\section{JORGE MANUEL, THEOTOCÓPULI TRACISTA Y ARQUITECTO DE LA IGLESIA DE LA SANTÍSIMA TRINIDAD DE TOLEDO, VERSUS PARROQUIA DE SAN MARCOS}

Los datos con que ahora contamos al respecto ${ }^{1}$, y que seguidamente reseñaremos, confirman sin paliativos todas las hipótesis —entonces, hipótesis fundadas, según diremos- que en su día hiciéramos sobre Jorge Manuel Theotocópuli (Toledo: 1578-1631) como tracista y arquitecto de la iglesia de la Santísima Trinidad de Toledo (trinitarios calzados) que, tras la exclaustración decimonónica, pasó a ser sede de la parroquia mozárabe de San Marcos ${ }^{2}$.

En un requerimiento judicial efectuado por el alcalde mayor de Toledo, se insta a que el convento de trinitarios calzados de la ciudad, mediante escritura pública y oficial, dé respuesta a una serie de cuestiones demandadas por el conde de Villafranca de Gaitán, quien, en pleito con el cenobio toledano, apoyándose en ostentar el patronazgo de la capilla mayor de su iglesia, requiere contestación precisa sobre el tema.

En realidad, el patronazgo ejercido por esta casa nobiliaria, se refería a la capilla mayor de la vieja iglesia trinitaria, que es demolida, dada su ruina acuciante, en 1628. A la explícita pregunta de si trata de construirse una nueva capilla mayor en la iglesia del citado convento toledano, éste, de modo rotundo y absolutamente diáfano según nuestro interés, responde: «que el Convento trata y desea sumamente hacer vna Capilla mayor de las más sumptuosas (sic, suntuosas), que ay ( $s i c$, hay) en la Ciudad como lo pide la planta, que para ello esta sacada ya, y la Capilla mayor en dibuxo trabaxada por Jorge Manuel Obrero (sic; debe decir: maestro) mayor ya difunto, como se podra ver y en esta Conformidad, quedan sacados los dentales (sic) para que se prosiga Con la Capilla mayor; y para que no aya (sic, haya) polbo (sic, polvo) en la Yglesia Con la Obra, en el interin que se hace, se cierra el Cuerpo de la yglesia con vn obalo (sic, óvalo) de tapia y pilares de ladrillo mui (sic, muy) poco levantado, con vnos taibiques (sic, tabiques) para que decentemente se pueda Celebrar» ${ }^{3}$.

\footnotetext{
1 Debemos su conocimiento a la amabilidad y generosidad de María Cruz de Carlos Varona, a quien desde aquí damos las gracias.

2 Al respecto, ver: Suárez Quevedo, D.: Arquitectura barroca en Toledo: siglo XVII, ed. Universidad Complutense de Madrid, colección: Tesis Doctorales, núm. 489/88. Madrid, 1988, tomo I, pp. 220-277 y tomo II, pp. 1.105-1.166; Idem: Arquitectura barroca en Toledo: siglo XVII. Toledo, 1990, pp. 125-151, e Idem: «El período barroco», en Arquitecturas de Toledo, ed. Servicio de Publicaciones de la Junta de Comunidades de Castilla-La Mancha. Toledo, 1991, vol. II, pp. 269-276.

3 Archivo Histórico Nacional, sección: Clero, legajo 7.442: «Papel sobre el Patronato contra los condes de Villafranca Gaitán»; tres folios sin ninguna ordenación numérica y carentes de fecha.
} 
La contundencia de los términos de la declaración trinitaria, es total y absoluta, explicitando que la nueva, y suntuosa, capilla mayor se realiza y construye «como lo pide la planta», es decir, la planta general del templo, «que para ello esta sacada ya»; y la citada capilla mayor, aún en fase de ejecución, «en dibuxo traxada por Jorge Manuel». El lapsus de obrero por maestro, resulta irrelevante, ya que el obrero mayor catedralicio era un cargo del organismo de la obra y fábrica, ostentado por un eclesiástico, usualmente un canónigo de la catedral de Toledo, y, en todos los sentidos, ajeno al hecho profesional de la arquitectura que, en sus más altas cotas, era cometido del maestro mayor de obras de la Primada, que fue el caso de Jorge Manuel Theotocópuli.

La expresión «quedan sacados los dentales», en conformidad con la planta general trazada, debe referirse a trazas parciales, para los trabajos efectivos en la práctica; es decir, «dentales» aludiría figuradamente a «endentecer», o sea, empezar los niños a echar los dientes que, aplicado a la obra constructiva, sería «echar sus dientes» desde los cimientos, según esas trazas parciales. Sí es usual en la época —o más usual, que sepamos-, y con ciertas similitudes, la expresión «sacar la obra de cimientos», que requería precisión, cuidado y supervisión casi siempre del arquitecto de la misma; se otorgaba al hecho de lograrlo, un cierto valor intelectual y profesional, como algo que, junto a la realización y elaboración de trazas, comportaba «trabajo, ingenio e industria», solía decirse.

Realizado ya entonces, c. 1634-35, básicamente el cuerpo de la nueva iglesia, es delimitado mediante un cerramiento temporal, «de tapia y pilares de ladrillo», que lo aisle de la capilla mayor y de sus obras, en forma de «obalo (sic, óvalo)», seguramente a modo de ábside provisional, que permita oficiar dignamente en el templo así reducido; es decir, de forma semicircular u oval.

Entre el 29 de marzo y el 4 de abril del citado año de 1628, se habían sucedido en Toledo una serie de declaraciones públicas, sobre la ruina de la antigua iglesia trinitaria, y la conveniencia y viabilidad de realizar la nueva, es decir, la que hoy sigue en pie, concluyéndose, en la última de las fechas señaladas, que debía construirse, contando, como así fue, con los consentimientos del consistorio de la ciudad y del padre provincial de la orden, entonces fray Hortensio Felix Paravicino. Entre los testigos declarantes al efecto, figuraba, entre otros varios, el propio Jorge Manuel Theotocópuli, a la sazón maestro mayor de obras de la catedral de Toledo, título y cargo que ostentó entre los años 1625 y 1631, es decir, hasta su fallecimiento.

El hijo de El Greco testimoniaba, con data en Toledo a 30 de marzo de 1628, la ruina irreversible de la vieja iglesia y apoyaba la idea y proyecto del nuevo templo trinitario, rubricándolo bajo juramento y ante escribano público, como era lo usual; lo hacía como «maestro mayor de obras de la ssancta (sic) yglessia de Toledo y de los alcaçares Reales de esta çiudad» 4 .

Lógicamente debía avalar el nuevo proyecto siendo su autor, como ahora sabemos fehacientemente; de todos modos, aún antes del testimonio anterior, existe un indicio bastante claro y certero sobre su autoría, tal como en su día argumentábamos, ya que la escritura protocolizada ${ }^{5}$, mediante la cual Francisco de Espinosa, maestro de obras toledano, contrataba las de la nueva iglesia trinitaria, con data en Toledo a 6 de febrero de 1628, consta de una muy elocuente cláusula, que prácticamente señala al tracista de la obra; se hacía constar que «si rresultare (sic) alguna duda para proseguir En la obra de la yglesia desde luego queda rremytido (sic) a que la declare Jorje (sic) manuel maesttro de obras y lo que declarare eso se a

Archivo Histórico Provincial de Toledo: Protocolo 2.270, 1628; escribanía de Blas Hurtado, fols. 386-386v.

Ibid.: Protocolo 3.010, 1628; escribanía de Juan Manuel de la Cuadra, fols. 594-595v. 
(sic, ha) de Cunplir (sic)». Lo cual, dentro de la terminología y lenguaje contractuales de la época, está apuntando claramente al tracista responsable de la obra en cuestión, como ya suponíamos e indicábamos, Jorge Manuel Theotocópuli; lo que ahora podemos comprobar y constatar sin duda alguna.

Diego SuÁREZ QUEVEDo

Universidad Complutense

\section{PEDRO DE MAYORGA: ¿EL MAESTRO DE PALANQUINOS?}

El Museo de la Iglesia de Oviedo posee desde su fundación en 1990 una pintura de finales del siglo XV que representa la Asunción de Nuestra Señora en presencia de un donante (óleo y temple/tabla, 87 x $88 \mathrm{~cm}$., cat. P 1, núm. inv. 213). Se trata de un depósito de la catedral ovetense que cuenta ya con algunas reseñas bibliográficas en el ámbito regional ${ }^{1}$. El soporte lo integran cinco tableros de pino encolados a arista viva, muy deteriorados por la carcoma, lo que interesó también a la pintura: casi una cuarta parte de su superficie se halla perdida. El aparejado es de yeso, con las juntas encañamadas. Fue restaurada en 1993 con motivo de la exposición Orígenes, donde figuró como anónima con la entrada número $289^{2}$.

En realidad, la obra procede del antiguo templo parroquial de Santa María del Naranco (Oviedo), establecido en el palacio altomedieval de Ramiro I (mediados del siglo IX). En ese emplazamiento la había descrito Miguel Vigil:

«Hay en la sacristía un cuadro pintado al óleo de 80 centímetros por lado con fondo dorado y buen dibujo: representa la Purísima Concepción adorada por cuatro ángeles vestidos y alados, viéndose el retrato del donante en actitud de orar, en la parte baja: pertenecía a fines del siglo XV o principios del siguiente, y conserva el marco original» $^{3}$.

Con toda probabilidad, la tabla provendría de aquel «retablo de costosas pinturas» que en 1856 menciona Francisco Javier Parcerisa, y que — sigue diciendo— fue reemplazado por el «pobre cura párroco [...] por otro de malísima talla» ${ }^{4}$.

La pintura fue depositada en la catedral por el cura ecónomo del Naranco el 23 de noviembre de 1931, firmando el recibo don Arturo Sandoval y Abellán, secretario capitular ${ }^{5}$. Desde esa fecha hasta su traslado al Museo, la tabla estuvo almacenada en las dependencias

1 Barón, Javier y González Santos, Javier, «Catálogo de las pinturas de la catedral de Oviedo», Liño, 7, Oviedo, Universidad de Oviedo, 1987, cat. 38, pp. 79-81. ÍD. e ÍD., «Corrigenda al catálogo de pinturas de la catedral de Oviedo», Liño, 9, Oviedo, 1990, cat. 38, p. 152. González Santos, Javier y Barón, Javier, La catedral de Oviedo y el Museo de la Iglesia, Oviedo, Fundación Municipal de Cultura del Ayuntamiento de Oviedo, 1995, p. 70. Platero Fernández-Candaosa, Ramón y Hevia Ballina, Agustín, «Museo de la Iglesia», en Guía de los Museos de Asturias, fascículo núm. 5, Oviedo, diario La Voz de Asturias, [1995], pp. 6 (reproducción) y 7 (texto). González Santos, Javier, ápud AA.VV., Catálogo del Museo de la Iglesia de Oviedo, cat. P 1 (en prensa) e ÍD., La catedral de Oviedo. Sancta Ovetensis, León, Edilesa, 1998, p. 103.

2 Paniagua Félix, Pedro, ápud Orígenes. Arte y cultura en Asturias. Siglos VII-XV, catálogo de la exposición celebrada en la catedral de Oviedo durante los meses de agosto-noviembre de 1993, Oviedo, 1993, pp. 461c462; sólo se reproduce un detalle: el busto de la Virgen y parte de un ángel del lado izquierdo de la tabla.

3 Miguel Vigil, Ciriaco, Asturias monumental, epigráfica y diplomática. Datos para la historia de la Provincia, vol. I, Oviedo, 1887, p. 218.

${ }^{4}$ Ápud Quadrado, José María, Recuerdos y bellezas de España. Asturias y León, Madrid, 1855, p. 247.

5 Archivo de la Catedral de Oviedo (A.C.O.): Papeles varios y curiosos, caja núm. 2, documento s/numerar. 